\title{
Prolonged Hypoxemia Enhances and Acute Hypoxemia Attenuates Laryngeal Reflex Apnea in Young Lambs ${ }^{1}$
}

\author{
MALGORZATA SLADEK, JENS B. GROGAARD, ROBERT A. PARKER, AND \\ HÅKAN W. SUNDELL \\ Departments of Pediatrics and Preventive Medicine. Vanderbilt University School of Medicine. \\ Nashville, Tennessee 37232-2585
}

\begin{abstract}
To determine the influence of an altered carotid body function on the laryngeal chemoreflex (LCR) response, reflex apnea was induced by laryngeal water stimulation during normoxia or acute hypoxia in unanesthetized awake lambs in which the ventilatory response to acute hypoxia was attenuated by prolonged postnatal hypoxemia. Prolonged hypoxemia $(\mathbf{H})$ was induced in seven lambs for $12 \mathrm{~d}$ after birth through exposure to 0.10 fraction of inspired oxygen. Five control lambs were kept in 0.21 fraction of inspired oxygen. Studies were performed repeatedly during the first 7 wk after birth. The ventilatory response to LCR stimulation, expressed as a percent decrease in minute ventilation, was tested in $0.21,0.14$, and 0.10 fraction of inspired oxygen. $H$ after birth resulted in a markedly increased inhibition of ventilation in response to LCR stimulation and postponed the age-related decrease in LCR response. A potential failure to recover from apnea occurred only in the $\mathrm{H}$ lambs, and in these lambs there was a significantly greater requirement for mechanical ventilation after LCR stimulation. Acute hypoxemia preceding LCR stimulation significantly attenuated the ventilatory response in both control and $H$ lambs, with a stronger effect in the $\mathrm{H}$ lambs. There was no difference between the two groups in heart rate response to $L C R$ stimulation. Acute hypoxemia significantly augmented reflex bradycardia in the $H$ lambs. These results show that there is a relationship between $\mathrm{H}$ immediately after birthwhich is known to delay resetting of carotid chemoreceptors-and augmented ventilatory inhibition in response to LCR stimulation. They do not confirm the theory that acute hypoxia reinforces reflex apnea. (Pediatr Res 34: 813-820, 1993)
\end{abstract}

\section{Abbreviations}

\section{C, control}

CB, carotid body

$\mathrm{FiO}_{2}$, fraction of inspired oxygen

$H$, prolonged hypoxemia (experimental group)

LCR, laryngeal chemoreflex

$\mathrm{PaCO}_{2}$, arterial partial pressure of $\mathrm{CO}_{2}$

$\mathrm{PaO}_{2}$, arterial partial pressure of $\mathrm{O}_{2}$

SIDS, sudden infant death syndrome

Received January 19, 1993; accepted July 27, 1993.

Correspondence: Hảkan W. Sundell, M.D. Professor of Pediatrics, Vanderbilt University Medical School, U-1212, MCN, Nashville. TN 37232-2585.

Supported by grants from the National Institutes of Health (HD22721 and HL14214).

'Presented in part at the annual meetings of the Society for Pediatric Research and the American Thoracic Society 1990.
SLN, superior laryngeal nerve

$\dot{\mathbf{V}}_{\mathbf{l}}$, minute ventilation

Prolonged apnea has been suggested as a possible cause of the SIDS (1-5). Because of its potential involvement in the etiology of SIDS, the cardiorespiratory reflex caused by laryngeal receptor stimulation has been studied intensively as a model of reflex apnea. Laryngeal receptors are sensitive to a wide range of stimuli (6-8), and reflex apnea resulting from laryngeal stimulation has been described in several animal species $(1,6,9)$ and in human infants $(10-12)$. The response is characterized by apnea, swallowing, bradycardia, hypertension, and blood flow redistribution (13). The magnitude of the response decreases with maturation (14-16). Electrical stimulation of the afferent SLN mimics the effects of laryngeal receptor stimulation by liquids such as water (17), and SLN denervation abolishes the reflex response (18). Inhibition of respiration beyond the SLN stimulation period has been shown by Lawson (19) to be of a central origin. He suggested that SLN stimulation activates a central neural mechanism that inhibits respiratory output for a prolonged period after the stimulus is discontinued.

The mechanism that promotes recovery from apnea, however, remains incompletely understood. The role of the peripheral chemoreceptor needs to be considered, inasmuch as the LCR apnea response is associated with a decrease in $\mathrm{PaO}_{2}$, which stimulates peripheral chemoreceptors (13). CB denervation significantly increased the apnea response after laryngeal stimulation in 2- to 4-wk-old lambs, but this response remained unchanged in younger lambs, suggesting that a mature $C B$ function plays a role in limiting reflex apnea caused by laryngeal water stimulation (14). However, it has been postulated that acute hypoxia preceding apnea induces a positive feedback that reinforces suppression of breathing, a mechanism that may play a role in the etiology of SIDS $(2,5,20)$. Recently, there has been much interest in the study of peripheral chemoreceptor function in infancy because of a possible relationship between hypoxic exposure, CB malfunction, and the SIDS (21-23). Further, alternation in respiratory reflexes has been postulated as a possible mechanism in SIDS (22).

This study was performed to determine the effect of acute and prolonged exposure to hypoxia on the ventilatory response to LCR stimulation in unanesthetized, awake lambs. The ventilatory response to acute hypoxia is weak shortly after birth and increases gradually during the first 1 to 2 wk after birth, during which time the $\mathrm{CB}$ sensitivity to abrupt changes in $\mathrm{PaO}_{2}$ is reset from the low range of $\mathrm{PaO}_{2}$ encountered in the fetus to higher postnatal levels. Studies in rats (24) and kittens (25) have demonstrated that the postnatal reset of $\mathrm{CB}$ can be delayed by prolonged hypoxemia after birth. We have shown that unanes- 
thetized, awake lambs kept hypoxemic for $12 \mathrm{~d}$ after birth also have a weak ventilatory response to acute hypoxic challenges for an extended period of time, indicating a delay in the postnatal reset of CB sensitivity to oxygen tension (26). To our knowledge, the effect of prolonged hypoxemia after birth on respiratory reflexes has not been described previously. This study was, therefore, undertaken in the same lambs to determine the influence of delayed resetting of CB oxygen sensitivity on the LCR apnea response.

\section{MATERIALS AND METHODS}

Twelve term lambs of mixed breed were used in this study. Seven lambs, forming the $\mathrm{H}$ group, were kept in a normobaric $0.85-\mathrm{m}^{3}$ chamber with $0.10 \mathrm{FiO}_{2}$ for $12 \mathrm{~d}$ after birth. The animals were continuously exposed to hypoxia except for $2-3 \mathrm{~h}$ after birth and for 15 -min periods five times a day for feeding, catheter care, and cleaning of the chamber. The oxygen concentration of the mixture of air and nitrogen was monitored continuously with an oxygen analyzer (Ventronics model 5525, Hudson, Ventronics Division, Temecula, CA). The total gas flow into the chamber was $21 \mathrm{~L} / \mathrm{min}$. To avoid an appreciable increase in $\mathrm{CO}_{2}, a \mathrm{CO}_{2}$ absorber was placed in the chamber. Intermittent monitoring revealed no appreciable increased $\mathrm{CO}_{2}$ concentration. The temperature was kept at $21-24^{\circ} \mathrm{C}$. Five lambs were used as a control (C) group and were kept in the normobaric chamber $\left(0.21 \mathrm{FiO}_{2}\right)$ with an airflow of $21 \mathrm{~L} / \mathrm{min}$ for $12 \mathrm{~d}$ after birth. Thereafter, the $\mathrm{H}$ and $\mathrm{C}$ lambs were reared with the ewes in room air. Both groups were nursed ad libitum.

$H$ lambs were studied at an age of $5 \mathrm{~d}$, at the end of hypoxia on d 11 to 14 (average age $12 \mathrm{~d}$ ), 2 to $4 \mathrm{~d}$ after return to room air (average age $16 \mathrm{~d}$ ), 6 to $7 \mathrm{~d}$ after return to room air (average age $19 \mathrm{~d}$ ), and weekly thereafter until $5 \mathrm{wk}$ after termination of hypoxia. C lambs were studied at the same time points. The number of animals studied at each time point varied from seven to four in the $\mathrm{H}$ group and from five to two in the $\mathrm{C}$ group. Two lambs died from the experimental manipulation. Some lambs could not be studied when they were older because they were too excitable.

The research protocol was approved by the Vanderbilt University Animal Care Committee.

Instrumentation. Using aseptic technique and local anesthesia, 3-d-old lambs were instrumented with placement of a low tracheostomy and catheters in the cranial tibial artery and lateral saphenous vein, as described previously (14). A 2 -inch segment of an endotracheal tube (Portex, Inc., Wilmington, MA) was inserted into the tracheostomy to allow the lambs to breath through the upper airway except for at the time of the studies. Antibiotics (gentamicin $4 \mathrm{mg} / \mathrm{kg}$ and carbenicillin $100 \mathrm{mg} / \mathrm{kg}$ ) were given daily from the time of instrumentation until the last study. A postoperative 48-h recovery period was allowed before the first study was performed. At the time of each study, the tracheostomy prosthesis was removed and through the trachoestoma a biluminal balloon catheter (Fr 8 Foley) was inserted and directed upward with the tip placed just below the vocal cords. A tight-fitting endotracheal tube (Portex 4.5-8) was directed downward. The balloons of the Foley catheter and the endotracheal tube were inflated, so water could be flashed retrograde through the larynx without compromising the ventilation. Lambs were breathing spontaneously through the endotracheal tube connected to a Baby Bird respirator (Bird Corp., Palm Springs, $\mathrm{CA}$ ) with continuous gas flow of $10 \mathrm{~L} / \mathrm{min}$. To maintain functional residual capacity, a continuous positive airway pressure of $2-3 \mathrm{~cm}$ of water was used to compensate for the effect of reduced upper airway tone due to the tracheostomy. $\mathrm{FiO}_{2}$ was changed without disturbing the animal by using a blender (Bird High Flow Oxygen Blender, model 2900, Bird Corp., Palm Springs, CA). A pneumotachograph (model 21070B, Hewlett-Packard, Waltham, MA) was interposed in between the endotracheal tube and the respirator.
Recordings. All recordings were made with an eight-channel Hewlett-Packard 7758B recording system. The pneumotachograph was connected to a differential pressure transducer (model 270, Hewlett-Packard) and to a respiratory integrator (model $8815 \mathrm{~A}$, Hewlett-Packard). For measurement of ventilation, the pneumotachograph flow signal was integrated to obtain $\dot{V}_{1}$. Statham transducers (model $23 \mathrm{FD}$, Gould-Statham, Oxnard, CA) were used for pressure and heart rate measurements. The lambs were monitored during the experimental period with continuous recordings of arterial pressure, heart rate, and serial blood gas analyses (Corning model 158, pH/Blood Gas Analyzer, Ciba Corning Diagnostics Corp., Medfield, MA).

Experimental protocol. On the day of the experiment, the lambs were brought to the laboratory and allowed to become familiar with the equipment. The lambs were studied unanesthetized, slightly restrained in a sling (Alice King Chatham, Medical Arts, Los Angeles, CA) while they were awake and relaxed (open eyes, regular breathing, and absence of body movement). The animals were studied only if their rectal temperature was normal $\left(39 \pm 0.5^{\circ} \mathrm{C}\right)$ and they had no sign of infection. The ambient temperature was $21-24^{\circ} \mathrm{C}$. Within $2 \mathrm{~h}$ of breathing 0.21 $\mathrm{FiO}_{2}$, the lambs were studied as described below. Each trial was begun when ventilation was judged to be stable and the lamb was quiet.

Laryngeal water stimulation. Each trial consisted of a 30-s baseline period of regular breathing followed by a retrograde injection of $1 \mathrm{~mL}$ of distilled water at room temperature through the Foley catheter during a 5-s period. Respiration, blood pressure, and heart rate were continuously monitored to indicate that the lambs had returned to the original baseline state before the next test was performed. A series of four water stimulations were performed in $0.21 \mathrm{FiO}_{2}$ and a series of two each in 0.14 and $0.10 \mathrm{FiO}_{2}$. Stimulation during acute hypoxemia was performed $15 \mathrm{~min}$ after the change in $\mathrm{FiO}_{2}$.

Use of mechanical ventilation. If the lamb remained apneic 30 $s$ after the onset of LCR stimulation, two mechanical breaths were administered by the respirator every $10 \mathrm{~s}$ until regular, spontaneous breathing was reestablished.

Interpretation of response and data analysis. The effect of LCR stimulation on ventilation was assessed as percent decrease in ventilation volume inspired during the 30 -s period after onset of the stimulus compared with the 30 -s baseline period immediately preceding stimulation. Duration of continuous apnea was measured in seconds. Recovery time was defined as the time in seconds elapsed from the onset of stimulation to the beginning of regular, spontaneous breathing for 10 consecutive seconds. Heart rate was calculated from the blood pressure tracing during a 3-s period at baseline and after the onset of the stimulus when the lowest value was attained (maximal bradycardia), which usually occurred 2 to $5 \mathrm{~s}$ after onset of stimulation and was expressed as percent decrease from baseline. Tests were accepted as valid if the pretest baseline was stable and free of visible oscillations and was not interrupted by sigh or cough.

Statistical methods. At each level of $\mathrm{FiO}_{2}$, the average of all LCR stimulations was used as the response for an animal for the study day. Results presented are mean \pm SEM. An unpaired $t$ test was used for comparison of individual observations between groups. Within a group, a paired $t$ test was used to assess the effect of different levels of $\mathrm{FiO}_{2}$. The general linear model was used to model overall results to assess whether prolonged hypoxemia merely delayed maturational changes in the response to LCR stimulation or whether it had an effect in addition to a time delay. This analysis compared results after adjusting for the duration of hypoxemia. For example, if prolonged hypoxemia merely delayed the maturational decrease in the response to LCR stimulation, then we would expect the results on d 16 for an animal in hypoxia for $12 \mathrm{~d}$, i.e. $4 \mathrm{~d}$ after the end of hypoxia, to be similar to those of a 5-d-old control animal. Thus, if the effect of hypoxemia is only to delay the CB reset, then the effect of treatment (hypoxemia or control) in this analysis would not be 
statistically significant. The model adjusted for the level of $\mathrm{O}_{2}$ in the hypoxic test $\left(0.14\right.$ or $\left.0.10 \mathrm{FiO}_{2}\right)$ treating $\mathrm{O}_{2}$ level as a categorical variable. Study number (in Clambs) or study number after hypoxemia (H lambs) was treated as a continuous variable, implying that the change in an outcome variable was linear over the time periods compared. In this model, we needed to allow for the fact that observations within a lamb are related. Because we were not interested in estimating results for specific lambs, however, we used a mixed model treating the lamb as a random effect within treatment. Significant differences were accepted for $p<0.05$

\section{RESULTS}

$\dot{V}_{1}$ and heart rate before laryngeal stimulation. Average $\dot{V}_{1}$ and heart rate values obtained before LCR in $0.21,0.14$, and 0.10 $\mathrm{FiO}_{2}$ are presented in Table 1 . At $26 \mathrm{~d}$ of age, the $\mathrm{H}$ lambs showed significantly higher $\dot{\mathrm{V}}_{1}$ in all three $\mathrm{FiO}_{2}$. For every other study, there was no significant difference in $\dot{V}_{1}$ among groups. Heart rate was significantly lower in the $\mathrm{H}$ lambs at $5 \mathrm{~d}$ of age in 0.21 and $0.10 \mathrm{FiO}_{2}$, and at $33 \mathrm{~d}$ in $0.14 \mathrm{FiO}_{2}$.

$\mathrm{PaO}_{2}$ and $\mathrm{PaCO}_{2}$ before laryngeal stimulation. Table 2 presents average $\mathrm{PaO}_{2}$ and $\mathrm{PaCO}_{2}$ values obtained before laryngeal stimulation in $0.21,0.14$, and $0.10 \mathrm{FiO}_{2}$. As expected, $\mathrm{PaO}_{2}$ varied with $\mathrm{FiO}_{2}$. There was a general tendency for the $\mathrm{H}$ group to have lower $\mathrm{PaO}_{2}$ compared with the $\mathrm{C}$ group. Statistically significant differences between the two groups were found at $12 \mathrm{~d}$ in 0.14 $\mathrm{FiO}_{2}$ and at $16 \mathrm{~d}$ in $0.21,0.14$, and $0.10 \mathrm{FiO}_{2} . \mathrm{PaCO}_{2}$ values decreased with decreasing $\mathrm{FiO}_{2}$ in both groups. At $5 \mathrm{~d}$ in 0.21 $\mathrm{FiO}_{2}, \mathrm{PaCO}_{2}$ was significantly lower in the $\mathrm{H}$ group compared with the $\mathrm{C}$ group, but $\mathrm{PaCO}_{2}$ was significantly higher in the $\mathrm{H}$ lambs at $16 \mathrm{~d}$ in 0.14 and $0.10 \mathrm{FiO}_{2}$ and at $19 \mathrm{~d}$ in $0.10 \mathrm{FiO}_{2}$.

Arterial $\mathrm{pH}$ before laryngeal stimulation. During the prolonged hypoxemia period, baseline $\mathrm{pH}$ at $5 \mathrm{~d}$, measured while the lambs were breathing $0.21 \mathrm{FiO}_{2}$, was $7.32 \pm 0.01$ in the $\mathrm{H}$ group and $7.35 \pm 0.01$ in the $C$ group (NS). At $12 \mathrm{~d}$, there was a statistically significant difference in $\mathrm{pH}$ between the groups [ $\mathrm{H}$ group, 7.27 $\pm 0.02 ; \mathrm{C}$ group, $7.36 \pm 0.02(p<0.05)]$. There were no statistically significant differences in $\mathrm{pH}$ between the two groups after discontinued prolonged hypoxemia. During acute hypoxemia, $\mathrm{pH}$ increased commensurate with the decrease in $\mathrm{PaCO}_{2}$. The only statistically significant difference between the groups was observed at $12 \mathrm{~d}$ when the $\mathrm{H}$ group continued to have significantly lower $\mathrm{pH}$ than the $\mathrm{C}$ group $[7.31 \pm 0.02$ versus 7.42 \pm 0.01 during $0.14 \mathrm{FiO}_{2}(p<0.001)$ and $7.34 \pm 0.01$ versus 7.51 \pm 0.01 during $0.10 \mathrm{FiO}_{2}(p<0.0001)$ ].
Ventilatory response to laryngeal stimulation in $0.21 \mathrm{FiO}_{2}$. Figure 1 shows the ventilatory response (percent decrease in ventilation volume) to laryngeal water stimulation in lambs breathing $0.21 \mathrm{FiO}_{2}$. In the $\mathrm{C}$ group, LCR stimulation had a progressively diminishing inhibitory effect on ventilation during the first $26 \mathrm{~d}$ after birth, after which time the response leveled off. In the $\mathrm{H}$ group, the ventilatory response was more pronounced than in the $\mathrm{C}$ group and was significantly different between the two groups at 12,16 , and $33 \mathrm{~d}$ (all $p<0.05$ ). An age-related decrease in the response was not seen until $7 \mathrm{~d}$ after discontinued prolonged hypoxemia.

Apnea duration and recovery time. Duration of initial apnea and recovery time after laryngeal water stimulation were longer in the $\mathrm{H}$ group compared with the $\mathrm{C}$ group. Figure 2 shows apnea duration and recovery time after laryngeal stimulation performed in lambs breathing $0.21 \mathrm{FiO}_{2}$. Similar patterns, although less pronounced, were seen after tests performed in 0.10 and $0.14 \mathrm{FiO}_{2}$ (data not shown).

Ventilatory response to laryngeal stimulation during acute hypoxia. Compared with normoxia, moderate or severe acute hypoxia $\left(0.14\right.$ or $\left.0.10 \mathrm{FiO}_{2}\right)$ attenuated the ventilatory response to laryngeal water stimulation in both control and hypoxic lambs (Fig. 3). The response to laryngeal stimulation was significantly less during acute hypoxia at $5,12,26$, and $33 \mathrm{~d}$ in the $\mathrm{C}$ group and at $12,16,19$, and $33 \mathrm{~d}$ in the $\mathrm{H}$ group. The ventilatory response to laryngeal stimulation in $0.14 \mathrm{FiO}_{2}$ was significantly increased in the $\mathrm{H}$ group compared with the $\mathrm{C}$ group at an age of 12 and $19 \mathrm{~d}$ and in $0.10 \mathrm{FiO}_{2}$ at 19,26 , and $47 \mathrm{~d}$.

Time shift analysis. Prolonged hypoxemia affected the ventilatory response, apnea duration, and recovery time more than could be explained by a simple time shift effect. There was a definite effect of prolonged hypoxemia, in addition to changes as the animals grew older, at different $\mathrm{FiO}_{2}$ levels on decrease of ventilation, duration of apnea, and recovery time (all $p<0.01$ ).

Need for mechanical ventilation. To interrupt apnea periods longer than $30 \mathrm{~s}$, two mechanical breaths were administered every $10 \mathrm{~s}$ until regular, spontaneous breathing was present. The need for mechanical ventilation after laryngeal stimulation is listed in Table 3. Mechanical ventilation was not needed in either study group after $\mathbf{d} 26$. There was a significantly greater need for mechanical ventilation in the $\mathrm{H}$ group $(p<0.0001)$. The need for mechanical ventilation significantly decreased with increasing age over the entire study period $(p<0.0001)$. Mechanical ventilation was used to terminate prolonged poststimulus apnea after $28(12.2 \%)$ of 230 laryngeal stimulations during the first five studies in the $\mathrm{H}$ group, but it was not needed during any of

Table 1. Baseline $\dot{V}_{I}\left(\mathrm{~mL} \cdot \mathrm{min}^{-1} \cdot \mathrm{kg}^{-1}\right)$ and heart rate (bpm) before $L C R$ performed in $0.21,0.14$, and $0.10 \mathrm{FiO}_{2}^{*}$

\begin{tabular}{|c|c|c|c|c|c|c|c|c|c|}
\hline \multirow{2}{*}{$\begin{array}{l}\text { Age } \\
\text { (d) }\end{array}$} & \multirow{2}{*}{$\begin{array}{l}\text { Time } \\
\text { after } \mathrm{H} \\
\text { (d) }\end{array}$} & \multirow[b]{2}{*}{ Group } & \multirow[b]{2}{*}{$n$} & \multicolumn{3}{|c|}{$\dot{\mathrm{V}}_{\mathbf{I}}$} & \multicolumn{3}{|c|}{ Heart rate } \\
\hline & & & & $0.21 \mathrm{FiO}_{2}$ & $0.14 \mathrm{FiO}_{2}$ & $0.10 \mathrm{FiO}_{2}$ & $0.21 \mathrm{FiO}_{2}$ & $0.14 \mathrm{FiO}_{2}$ & $0.10 \mathrm{FiO}_{2}$ \\
\hline \multirow[t]{2}{*}{5} & & $\mathrm{C}$ & 5 & $512 \pm 56$ & $635 \pm 64$ & $771 \pm 52$ & $268 \pm 8$ & $274 \pm 5$ & $310 \pm 9$ \\
\hline & & $\mathbf{H}$ & 5 & $466 \pm 19$ & $532 \pm 22$ & $550 \pm 19$ & $235 \pm 12 \dagger$ & $264 \pm 15$ & $278 \pm 8 \dagger$ \\
\hline \multirow[t]{2}{*}{12} & & $\mathrm{C}$ & 5 & $453 \pm 36$ & $543 \pm 46$ & $640 \pm 68$ & $240 \pm 11$ & $251 \pm 17$ & $263 \pm 28$ \\
\hline & & $\mathbf{H}$ & 7 & $450 \pm 31$ & $499 \pm 36$ & $551 \pm 42$ & $214 \pm 17$ & $226 \pm 7$ & $252 \pm 9$ \\
\hline \multirow[t]{2}{*}{16} & 4 & $\mathrm{C}$ & 4 & $430 \pm 28$ & $506 \pm 63$ & $527 \pm 14$ & $234 \pm 8$ & $270 \pm 18$ & $271 \pm 16$ \\
\hline & & $\mathrm{H}$ & 6 & $376 \pm 31$ & $445 \pm 33$ & $483 \pm 33$ & $212 \pm 20$ & $269 \pm 13$ & $285 \pm 9$ \\
\hline \multirow[t]{2}{*}{19} & 7 & C & 4 & $381 \pm 32$ & $489 \pm 15$ & $575 \pm 33$ & $221 \pm 9$ & $268 \pm 24$ & $265 \pm 15$ \\
\hline & & $\mathrm{H}$ & 6 & $368 \pm 36$ & $429 \pm 47$ & $520 \pm 28$ & $200 \pm 14$ & $213 \pm 14$ & $292 \pm 15$ \\
\hline \multirow[t]{2}{*}{26} & 14 & $\mathrm{C}$ & 4 & $249 \pm 11$ & $297 \pm 22$ & $383 \pm 19$ & $209 \pm 7$ & $230 \pm 18$ & $259 \pm 22$ \\
\hline & & $\mathrm{H}$ & 4 & $349 \pm 9 \dagger$ & $388 \pm 11 \dagger$ & $453 \pm 9+$ & $198 \pm 13$ & $203 \pm 16$ & $254 \pm 16$ \\
\hline \multirow[t]{2}{*}{33} & 21 & $\mathrm{C}$ & 4 & $242 \pm 27$ & $327 \pm 32$ & $362 \pm 39$ & $199 \pm 5$ & $260 \pm 14$ & $255 \pm 17$ \\
\hline & & $\mathrm{H}$ & 5 & $296 \pm 17$ & $354 \pm 23$ & $405 \pm 28$ & $184 \pm 15$ & $188 \pm 14 \dagger$ & $251 \pm 15$ \\
\hline \multirow[t]{2}{*}{40} & 28 & $\mathrm{C}$ & 3 & $295 \pm 20$ & $338 \pm 30$ & $473 \pm 94$ & $187 \pm 12$ & $217 \pm 22$ & $265 \pm 9$ \\
\hline & & $\mathrm{H}$ & 4 & $266 \pm 16$ & $306 \pm 25$ & $421 \pm 62$ & $168 \pm 25$ & $198 \pm 23$ & $250 \pm 15$ \\
\hline \multirow[t]{2}{*}{47} & 35 & $\mathrm{C}$ & 2 & $237 \pm 1$ & $276 \pm 8$ & $300 \pm 21$ & $184 \pm 14$ & $200 \pm 0$ & $223 \pm 3$ \\
\hline & & $\mathrm{H}$ & 5 & $268 \pm 36$ & $325 \pm 40$ & $371 \pm 37$ & $172 \pm 8$ & $180 \pm 13$ & $245 \pm 12$ \\
\hline
\end{tabular}

* Values are mean \pm SEM. $n$, number of animals.

+ Different from $C$ at $p<0.05$. 
Table 2. $\mathrm{PaO}_{2}$ and $\mathrm{PaCO}_{2}(\mathrm{kPa})$ preceding laryngeal chemoreflex stimulation*

\begin{tabular}{|c|c|c|c|c|c|c|c|c|}
\hline \multirow{2}{*}{$\begin{array}{l}\text { Age } \\
\text { (d) }\end{array}$} & \multirow{2}{*}{$\begin{array}{l}\text { Time } \\
\text { after } \mathrm{H} \\
\text { (d) }\end{array}$} & \multirow[b]{2}{*}{ Group } & \multicolumn{2}{|c|}{$0.21 \mathrm{FiO}_{2}$} & \multicolumn{2}{|c|}{$0.14 \mathrm{FiO}_{2}$} & \multicolumn{2}{|c|}{$0.10 \mathrm{FiO}_{2}$} \\
\hline & & & $\mathrm{PaO}_{2}$ & $\mathrm{PaCO}_{2}$ & $\mathrm{PaO}_{2}$ & $\mathrm{PaCO}_{2}$ & $\mathrm{PaO}_{2}$ & $\mathrm{PaCO}_{2}$ \\
\hline \multirow[t]{2}{*}{5} & & C & $12.7 \pm 0.5$ & $5.2 \pm 0.1$ & $5.7 \pm 0.5$ & $4.5 \pm 0.1$ & $3.9 \pm 0.2$ & $4.1 \pm 0.1$ \\
\hline & & $\mathrm{H}$ & $11.4 \pm 0.5$ & $4.5 \pm 0.3+$ & $5.1 \pm 0.1$ & $4.4 \pm 0.1$ & $3.2 \pm 0.1$ & $4.2 \pm 0.2$ \\
\hline \multirow[t]{2}{*}{12} & & C & $11.9 \pm 0.5$ & $5.0 \pm 0.2$ & $6.2 \pm 0.5$ & $4.7 \pm 0.2$ & $3.6 \pm 0.1$ & $3.8 \pm 0.0$ \\
\hline & & $\mathrm{H}$ & $11.1 \pm 0.4$ & $4.7 \pm 0.2$ & $4.7 \pm 0.4 \dagger$ & $4.5 \pm 0.1$ & $3.1 \pm 0.2$ & $4.0 \pm 0.1$ \\
\hline \multirow[t]{2}{*}{16} & 4 & $\mathrm{C}$ & $12.7 \pm 0.3$ & $5.5 \pm 0.4$ & $6.0 \pm 0.3$ & $4.5 \pm 0.2$ & $4.2 \pm 0.1$ & $3.6 \pm 0.1$ \\
\hline & & H & $10.9 \pm 0.5 \dagger$ & $5.6 \pm 0.3$ & $4.7 \pm 0.2+$ & $5.2 \pm 0.2 \dagger$ & $3.1 \pm 0.1 \dagger$ & $4.4 \pm 0.2 \dagger$ \\
\hline \multirow[t]{2}{*}{19} & 7 & $\mathrm{C}$ & $12.3 \pm 0.5$ & $5.1 \pm 0.3$ & $5.7 \pm 0.3$ & $4.7 \pm 0.3$ & $4.0 \pm 0.3$ & $3.6 \pm 0.1$ \\
\hline & & $\mathrm{H}$ & $11.5 \pm 0.4$ & $5.4 \pm 0.1$ & $5.4 \pm 0.1$ & $4.9 \pm 0.1$ & $3.5 \pm 0.1$ & $4.2 \pm 0.1+$ \\
\hline \multirow[t]{2}{*}{26} & 14 & $\mathrm{C}$ & $12.7 \pm 0.5$ & $5.2 \pm 0.2$ & $5.9 \pm 0.6$ & $4.4 \pm 0.1$ & $4.1 \pm 0.3$ & $3.7 \pm 0.1$ \\
\hline & & $\mathrm{H}$ & $11.9 \pm 0.1$ & $5.0 \pm 0.2$ & $5.3 \pm 0.4$ & $4.4 \pm 0.1$ & $3.5 \pm 0.1$ & $3.8 \pm 0.1$ \\
\hline \multirow[t]{2}{*}{33} & 21 & $\mathrm{C}$ & $12.0 \pm 0.3$ & $5.2 \pm 0.1$ & $5.4 \pm 0.3$ & $4.3 \pm 0.3$ & $4.0 \pm 0.2$ & $3.8 \pm 0.1$ \\
\hline & & $\mathrm{H}$ & $11.6 \pm 0.3$ & $5.0 \pm 0.2$ & $5.2 \pm 0.3$ & $4.3 \pm 0.2$ & $3.5 \pm 0.2$ & $3.7 \pm 0.1$ \\
\hline \multirow[t]{2}{*}{40} & 28 & $\mathrm{C}$ & $11.9 \pm 0.2$ & $5.1 \pm 0.3$ & $5.8 \pm 0.4$ & $4.5 \pm 0.1$ & $4.3 \pm 0.5$ & $3.6 \pm 0.2$ \\
\hline & & $\mathrm{H}$ & $11.5 \pm 0.3$ & $4.9 \pm 0.3$ & $5.4 \pm 0.3$ & $4.7 \pm 0.1$ & $3.9 \pm 0.2$ & $3.8 \pm 0.2$ \\
\hline \multirow[t]{2}{*}{47} & 35 & $\mathrm{C}$ & $12.3 \pm 0.3$ & $5.1 \pm 0.0$ & $5.7 \pm 0.5$ & $4.3 \pm 0.1$ & $3.8 \pm 0.3$ & $3.7 \pm 0.1$ \\
\hline & & $\mathrm{H}$ & $11.9 \pm 0.4$ & $5.3 \pm 0.1$ & $5.7 \pm 0.3$ & $4.7 \pm 0.1$ & $3.9 \pm 0.2$ & $3.8 \pm 0.1$ \\
\hline
\end{tabular}

* Values are mean $\pm \mathrm{SEM}$.

+ Different from control at $p<0.05$.

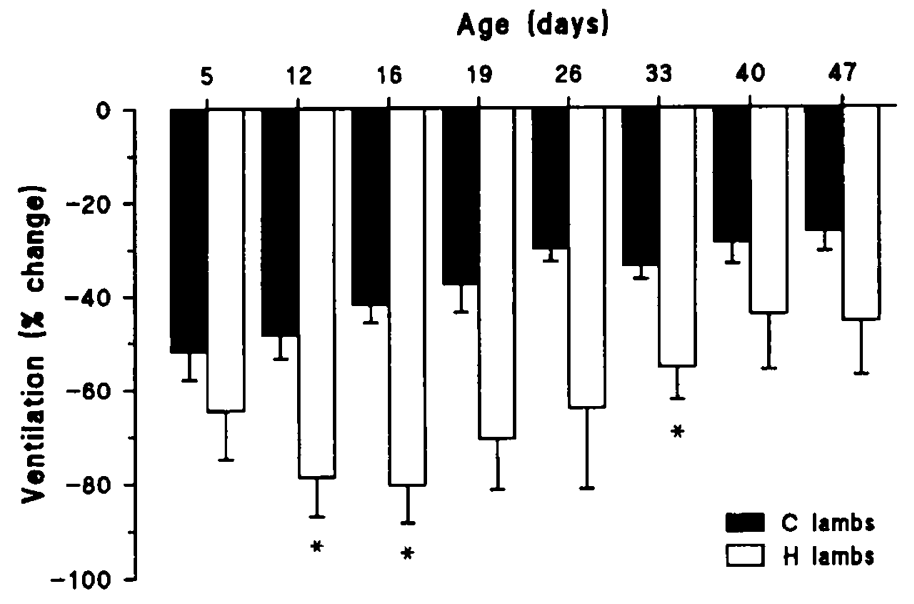

Fig. 1. Ventilatory response (percent change in ventilation volume during $30 \mathrm{~s}$ ) to laryngeal water stimulation performed in $0.21 \mathrm{FiO}_{2}$ in five $C$ lambs and in seven $\boldsymbol{H}$ lambs, which experienced prolonged hypoxemia for the first 12 postnatal days (mean $\pm \mathrm{SEM}$ ). ${ }^{*}, p<0.05$ for difference between groups.

the studies in the $\mathrm{C}$ group. $\mathrm{FiO}_{2}$ level did not significantly affect the need for mechanical ventilation after laryngeal stimulation.

Heart rate response. Figure 4 shows the heart rate response (percent decease in heart rate from baseline) to LCR stimulation in the $\mathrm{C}$ and $\mathrm{H}$ lambs. In addition to the differences due to $\mathrm{FiO}_{2}$ level shown in Figure 4, the heart rate response showed a linear decrease with increasing postnatal age in the control lambs (multiple linear regression, $p<0.001$ ). In the $\mathrm{H}$ lambs, there was both a significant linear effect $(p<0.001)$ and a quadratic effect $(p<0.01)$ reflecting that the most marked effect was on $\mathrm{d} 12$ to 19. There were no significant differences in the heart rate response to laryngeal stimulation between the $\mathrm{C}$ and the $\mathrm{H}$ lambs, whether the test was performed in $0.21,0.14$, or $0.10 \mathrm{FiO}_{2}$ Within the $\mathrm{C}$ group, only one significant difference was found when the heart rate response was compared between various $\mathrm{FiO}_{2}$ (Fig. 4A). Within the $\mathrm{H}$ group, the heart rate response was significantly increased in $0.10 \mathrm{FiO}_{2}$ compared with $0.21 \mathrm{FiO}_{2}$ at an age of 5,12 , and $26 \mathrm{~d}$ and in $0.14 \mathrm{FiO}_{2}$ compared with 0.21 $\mathrm{FiO}_{2}$ at an age of $16 \mathrm{~d}$.

Correlation of ventilatory response and heart rate response. There was a substantial correlation between the ventilatory response and heart rate response to laryngeal stimulation. The
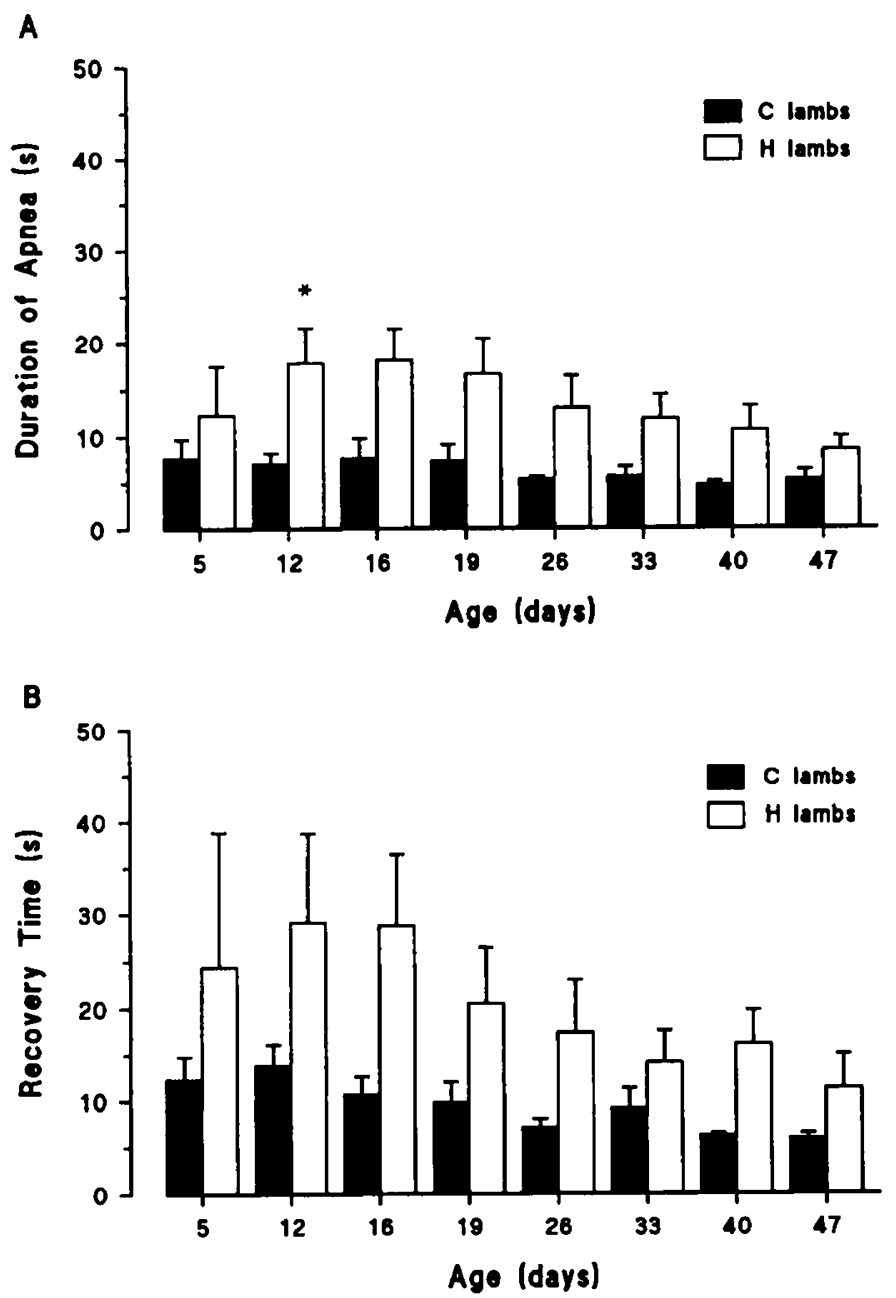

Fig. 2. Initial apnea duration $(A)$ and recovery time (time until regular breathing) $(B)$ after laryngeal water stimulation performed in $0.21 \mathrm{FiO}_{2}$ in five $\mathrm{C}$ lambs and in seven $\mathrm{H}$ lambs, which experienced prolonged hypoxemia for the first 12 postnatal days (mean \pm SEM). ${ }^{*}, p$ $<0.05$ for difference between groups. 

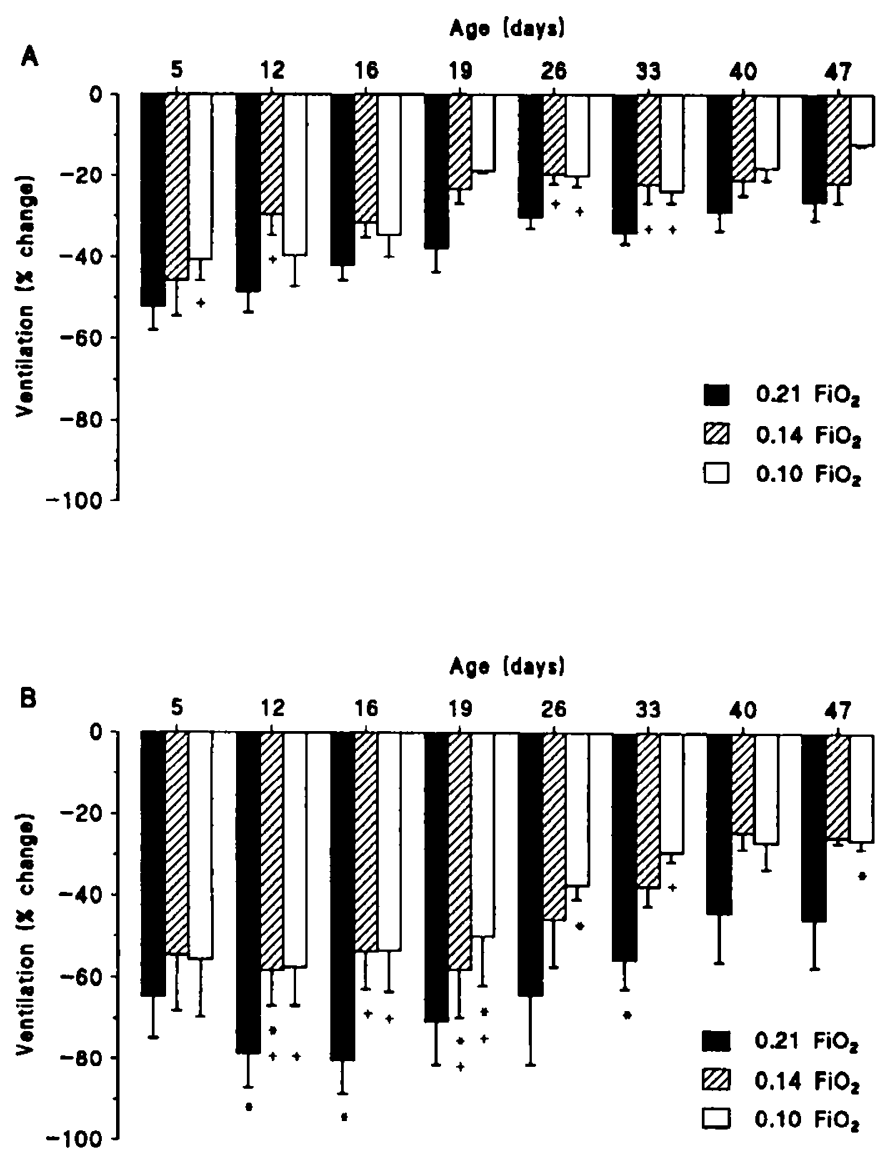

Fig. 3. Ventilatory response (percent change in ventilation volume during $30 \mathrm{~s}$ ) to laryngeal water stimulation performed in $0.21,0.14$, and $0.10 \mathrm{FiO}_{2}$ in five $\mathrm{C}$ lambs $(A)$ and in seven $\mathrm{H}$ lambs, which experienced prolonged hypoxemia for the first 12 postnatal days $(B)$ (mean $\pm \mathrm{SEM}$ ). ,$+ p<0.05$ for difference in response compared with $0.21 \mathrm{FiO}_{2} ;{ }^{*}, p<$ 0.05 for difference in response compared with $C$ lambs.

Spearman rank correlation was $0.66(p<0.0001)$ for all 74 observations at $0.21 \mathrm{FiO}_{2}$, and consistent results were found for each individual animal and for each group separately. The Spearman correlation for the $C$ group was $0.468(n=31, p<0.01)$ and for the $\mathrm{H}$ group was $0.810(n=43, p<0.001)$. The correlation between the ventilatory response and the heart rate response was stronger for the $\mathrm{H}$ group than for the $\mathrm{C}$ group ( $p$ $<0.05$ ). There was also a significant interaction between group and heart rate when predicting the ventilatory response $(p<$ $0.01)$.

\section{DISCUSSION}

Results from this study show that the ventilatory response (percent decrease in ventilation volume) to laryngeal water stimulation is attenuated by preceding acute hypoxemia in awake and unanesthetized lambs. In contrast, prolonged hypoxemia after birth results in a markedly increased inhibitory effect on ventilation in response to laryngeal stimulation. Control lambs showed a maturational decrease in the reflex response during the first 4 postnatal weeks, whereas in lambs kept hypoxemic for a prolonged time after birth the age-related decrease in response was not seen until $7 \mathrm{~d}$ after completion of hypoxemia. Laryngeal stimulation induced a prolonged disturbance of respiratory pattern demonstrated by a delayed onset of regular breathing in lambs kept hypoxemic for a prolonged time. During the first five studies (through d 26), these lambs demonstrated a potential failure to recover from apnea.

Others have also shown an age-related decrease in the LCR response $(2,14-16)$, but the mechanism inducing the maturational changes remains obscure. There is evidence showing that, in sheep, laryngeal receptor properties are unaffected by age (9) and afferent activity from laryngeal receptors is much the same in newborn and adult animals (6). Therefore, the decreasing response with age to laryngeal receptor stimulation should not be caused by a change in the total afferent input from the larynx. It is postulated that the magnitude of the response is modified by central neural activity (19). It is unclear whether the prolonged apnea in the young animals is caused by a less potent respiratory drive, greater susceptibility to suppression, or reduced central or/ and peripheral response thresholds.

Cessation of breathing causes a decreased $\mathrm{PaO}_{2}$ and an increased $\mathrm{PaCO}_{2}$, which stimulate peripheral and central chemoreceptors leading to an increased central respiratory drive and termination of the apnea reflex response (13). The ventilatory response to acute hypoxia increases progressively during the first 2 postnatal weeks and is related to maturational changes in the peripheral chemoreceptors principally located in the CB (14). The greater ventilatory inhibition in response to LCR stimulation in the first postnatal weeks may be related to a reduced $C B$ sensitivity to changes in $\mathrm{PaO}_{2}$ (14). In our study, it is likely that the progressively decreasing ventilatory response to LCR stimulation observed during the first 4 postnatal weeks in the control lambs is related to maturation of CB function, inasmuch as these same lambs had an increasing ventilatory response to hypoxia or hyperoxia during this time (26). The ventilatory inhibition in response to laryngeal water stimulation was significantly increased in the $\mathrm{H}$ lambs compared with the $\mathrm{C}$ lambs during the first 5 postnatal weeks, which coincides with the time during which these lambs showed a decreased ventilatory response to acute hypoxia (26). It is likely therefore that the increased LCR response observed in this study is related to an alteration in $\mathrm{CB}$

Table 3. Use of mechanical ventilation after laryngeal stimulation*

\begin{tabular}{|c|c|c|c|c|c|c|c|c|}
\hline \multirow[b]{2}{*}{$\begin{array}{l}\text { Age } \\
\text { (d) }\end{array}$} & \multirow[b]{2}{*}{$\begin{array}{l}\text { Time } \\
\text { after } \mathrm{H} \\
\text { (d) }\end{array}$} & \multirow[b]{2}{*}{ Group } & \multicolumn{2}{|c|}{$0.21 \mathrm{FiO}_{2}$} & \multicolumn{2}{|c|}{$0.14 \mathrm{FiO}_{2}$} & \multicolumn{2}{|c|}{$0.10 \mathrm{FiO}_{2}$} \\
\hline & & & $\begin{array}{c}\text { Ventilator } \\
\text { used/total } \\
\text { number of tests }\end{array}$ & $\%$ & $\begin{array}{c}\text { Ventilator } \\
\text { used/total } \\
\text { number of tests }\end{array}$ & $\%$ & $\begin{array}{c}\text { Ventilator } \\
\text { used/total } \\
\text { number of tests }\end{array}$ & $\%$ \\
\hline \multirow[t]{2}{*}{5} & & $\mathrm{C}$ & $0 / 20$ & 0 & $0 / 8$ & 0 & $0 / 10$ & 0 \\
\hline & & $\mathrm{H}$ & $3 / 18$ & 17 & $2 / 10$ & 20 & $1 / 9$ & 11 \\
\hline \multirow[t]{2}{*}{12} & & C & $0 / 20$ & 0 & $0 / 10$ & 0 & $0 / 10$ & 0 \\
\hline & & $\mathrm{H}$ & $6 / 28$ & 21 & $1 / 13$ & 8 & $1 / 12$ & 8 \\
\hline \multirow[t]{2}{*}{16} & 4 & $\mathrm{C}$ & $0 / 16$ & 0 & $0 / 8$ & 0 & $0 / 8$ & 0 \\
\hline & & $\mathrm{H}$ & $5 / 28$ & 18 & $2 / 14$ & 14 & $1 / 13$ & 8 \\
\hline \multirow[t]{2}{*}{19} & 7 & $\mathrm{C}$ & $0 / 15$ & 0 & $0 / 8$ & 0 & $0 / 8$ & 0 \\
\hline & & $\mathrm{H}$ & $2 / 24$ & 8 & $2 / 12$ & 17 & $1 / 10$ & 10 \\
\hline \multirow[t]{2}{*}{26} & 14 & $\mathrm{C}$ & $0 / 16$ & 0 & $0 / 8$ & 0 & $0 / 8$ & 0 \\
\hline & & $\mathrm{H}$ & $1 / 20$ & 5 & $0 / 9$ & 0 & $0 / 10$ & 0 \\
\hline
\end{tabular}

\footnotetext{
* Mechanical ventilation was not needed in subsequent studies.
} 

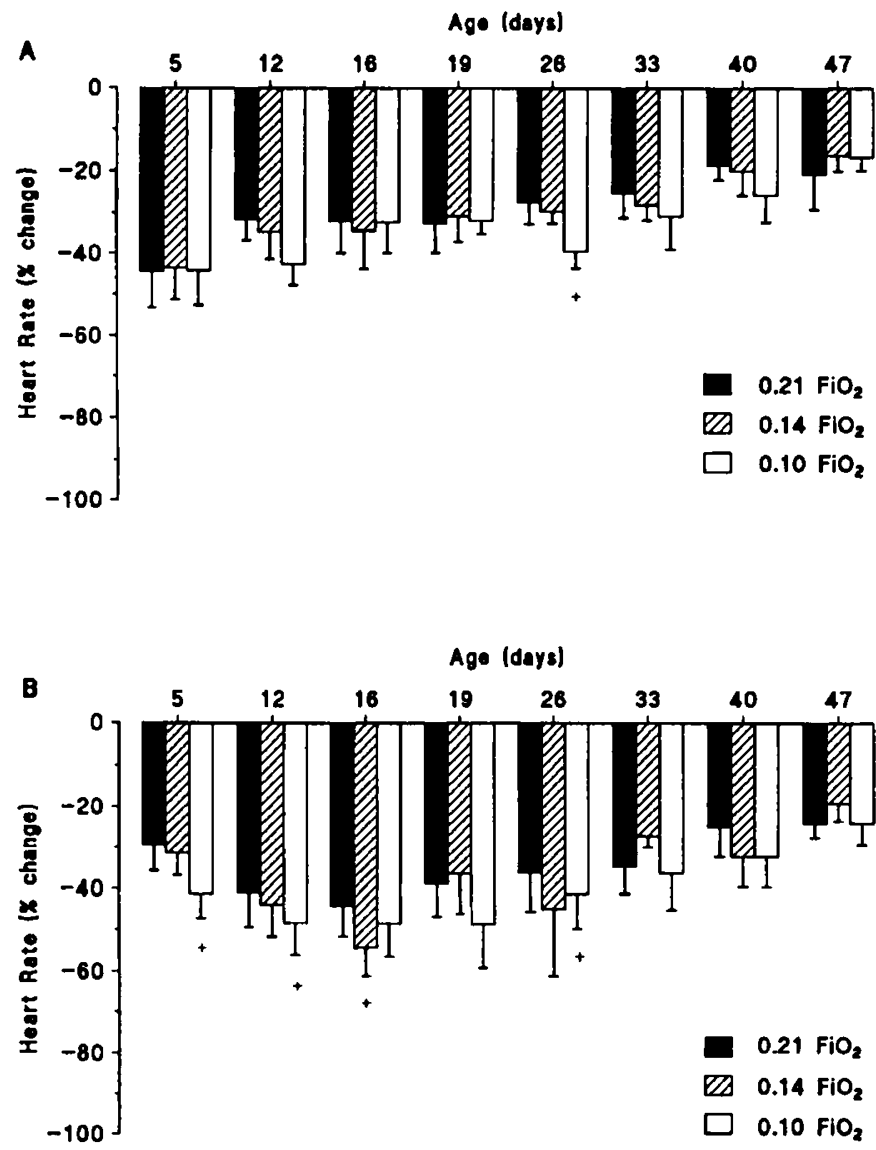

Fig. 4. Heart rate response (maximum percent change from baseline) to laryngeal water stimulation performed in $0.21,0.14$, and $0.10 \mathrm{FiO}_{2}$ in five $C$ lambs $(A)$ and in seven $\mathrm{H}$ lambs, which experienced prolonged hypoxemia for the first 12 postnatal days $(B)$ (mean \pm SEM).,$+ p<$ 0.05 for difference in response compared with $0.21 \mathrm{FiO}_{2} ;{ }^{*}, p<0.05$ for difference in response compared with $\mathrm{C}$ lambs.

function induced by prolonged hypoxemia. It is of interest to note that hypoxemia during the first 12 postnatal days had a prolonged effect on the LCR response and did not merely represent a 12-d delay in the normal postnatal maturation of the response.

An additional or alternative explanation for these results may be considered. Prolonged hypoxemia after birth may alter central mechanisms that control the magnitude of the ventilatory response to acute hypoxia as well as to apnea reflex stimulations $(27,28)$. Studies in adult cats exposed to prolonged hypoxia have shown that the peripheral chemoreceptor responsiveness to acute hypoxia is decreased and that the CNS translation of chemoreceptor input is attenuated (29). Possible support for an altered central mechanism in these studies comes from the fact that the ventilatory response to hyperoxia, which is often used to evaluate CB function, had normalized within $4 \mathrm{~d}$ after $\mathrm{H}$ lambs were returned to room air, whereas the ventilatory response to acute hypoxia remained attenuated for at least $35 \mathrm{~d}$ (26). We have, however, interpreted this apparent discrepancy to mean that the tonic activity of the $\mathrm{CB}$, as measured by the hyperoxia test, is rapidly normalized after discontinued prolonged hypoxemia, whereas the responsiveness to hypoxia is suppressed for an extended time.

It may be argued that prolonged hypoxemia has a general depressant effect on brain neurons including respiratory neurons that would then interfere with an adequate output and account for the enhanced inhibitory effect on ventilation in response to laryngeal stimulation. In this study, indices of central respiratory drive (occlusion pressure and mean inspiratory flow) were not significantly different between the groups at baseline (data not shown), and the respiratory center remained responsive to both moderate and severe hypoxemia per se (26). If the smaller ventilatory response to an acute decrease in $\mathrm{FiO}_{2}$ in the $\mathrm{H}$ group had been caused by a depression in the function of the neurons of the respiratory centers, then the more severe hypoxia $(0.10$ $\mathrm{FiO}_{2}$ ) would not be able to cause a greater response than moderate hypoxia $\left(0.14 \mathrm{FiO}_{2}\right)(26)$.

Whether studied in $\mathrm{C}$ lambs or in $\mathrm{H}$ lambs, inhibition of ventilation in response to laryngeal stimulation during moderate or severe acute hypoxia was always less than during normoxia. Several mechanisms may contribute to the reduced LCR response. The attenuated apnea reflex response during acute hypoxia compared with normoxia may be explained by preceding hypoxic respiratory stimulation (Table 1). Acute hypoxia may influence the central integration (30), which is determining the net response to laryngeal stimulation. Analogous attenuation of the LCR response is seen during hypercarbia (31) and after pretreatment with pharmacologic agents that stimulate respiration, e.g. aminophylline (3) and $\beta$-adrenergic agents (14). Conversely, the apneic response to laryngeal stimulation is enhanced by chloralose (3) or alcohol (32), which reduce the respiratory drive. In addition, lower $\mathrm{PaO}_{2}$ are reached during the apnea response when stimulated during preceding hypoxia compared with normoxia, which will evoke a more powerful stimulation of the CB chemoreceptive drive and contribute to the ultimate resumption of spontaneous ventilation after LCR.

In this study, $\mathrm{CO}_{2}$ was not controlled. If marked differences had been present in $\mathrm{PaCO}_{2}$, they could have influenced the results. A statistically significant difference in baseline $\mathrm{PaCO}_{2}$ during the studies performed in room air was only found at d 5 when $\mathrm{PaCO}_{2}$ was slightly lower in the $\mathrm{H}$ group compared with the $\mathrm{C}$ group. However, there was no significant difference in $\mathrm{pH}$ due to a slight metabolic acidosis in the $\mathrm{H}$ group. After $12 \mathrm{~d}$ of prolonged hypoxemia, $\mathrm{PaCO}_{2}$ was not significantly different between the groups, but $\mathrm{pH}$ was lower in the $\mathrm{H}$ group due to persistent metabolic acidosis. In spite of a possible stimulating effect from acidosis on respiratory drive at d 12 , baseline ventilation was not significantly different between the two groups, yet the inhibitory effect on ventilation in response to laryngeal stimulation was markedly augmented in the $\mathrm{H}$ group. If acidosis had influenced the magnitude of the response in the $\mathrm{H}$ lambs, we would have expected to see a decreased rather than an increased response.

Hyperventilation during acute hypoxemia induced mild hypocapnia in both groups of lambs that was only significantly different between the groups at 16 and $19 \mathrm{~d}$ of age when the $C$ group had lower $\mathrm{PaCO}_{2}$ compared with the $\mathrm{H}$ group. Although baseline ventilation was not significantly different between the groups, the significantly increased inhibitory effect on ventilation in response to laryngeal stimulation during acute hypoxemia in the $\mathrm{H}$ lambs at $19 \mathrm{~d}$ of age may have been related to a weaker respiratory drive as reflected in higher baseline $\mathrm{PaCO}_{2}$.

Others have shown that acute hypoxemia preceding laryngeal stimulation results in a reinforced cardiorespiratory response that may be fatal $(2,5)$. They postulated that this combination may be a possible mechanism for SIDS. Acute hypoxemia augmented the laryngeal reflex apnea response in studies performed on anesthetized piglets by Lanier et al. (2). It is possible that the difference between their results and ours may be explained by their use of ketamine as an anesthetic agent; our study was performed on awake and unanesthetized lambs. Anesthetic agents can influence the ventilatory response to laryngeal water stimulation $(3,33)$, and ketamine in particular impairs the mechanism responsible for initiating breathing after laryngeal reflex apnea (34). Ketamine is a hypoxic respiratory drive suppressor (35) and inhibits CB respiratory stimulation by blocking central synaptic transmission, which is necessary for integration of the chemoreceptor reflex (36).

Bradycardia is a characteristic component of the LCR response, and the magnitude of this response decreased with in- 
creasing postnatal age in the $\mathrm{C}$ lambs, whereas an initial increasing response was seen in the $\mathrm{H}$ lambs. A combination of several mechanisms is responsible for initiating and potentiating bradycardia during reflex apnea (37). Bradycardia is vagally mediated and is believed to be caused by laryngeal receptor stimulation (38), cessation of rhythmic pulmonary afferent traffic secondary to discontinued stimulation of pulmonary stretch receptors (38, 39 ), and CB stimulation (39). In a previous study using young, unanesthetized lambs (13), we showed that the heart rate response to laryngeal water stimulation performed in room air consists of an interaction of primary LCR response (one fourth of total response) as well as secondary effects from cessation of the pulmonary inflation reflex (one half of total response) and from hypoxic stimulation of the arterial chemoreceptor (one fourth of total response)

Input from the larynx affects the chemoreceptor respiratory and cardiac reflex responses in opposite ways. Whereas the $C B$ respiratory reflex is inhibited, the cardio-inhibitory reflex is greatly enhanced by impulses from both groups of receptors $(40$, 41 ). With further hypoxemia due to respiratory cessation, $C B$ stimulation that may overcome the apnea occurs. Engagement of the peripheral chemoreceptors is evident in progressive development of bradycardia throughout the apneic period (41). However, studies in newborn infants have shown that heart deceleration observed immediately after the onset of central apnea cannot be related to a decrease in $\mathrm{PaO}_{2}$ immediately after respiratory cessation $(42,43)$.

It seems unlikely that the major part of the observed heart rate response during normoxia in our study is dependent on $C B$ stimulation, because maximum bradycardia occurred shortly after the onset of stimulation and may be mostly related to stimulation of central mechanisms that trigger cardiac inhibition as well as heart rate deceleration related to absence of respiratory movements. Additionally, with increasing age, our $C$ lambs showed less bradycardia in response to LCR stimulation, the opposite of what would be expected if $C B$ influenced the maturational changes in the observed cardiac response.

A study in anesthetized dogs (38) and a study performed in sleeping human infants who previously had sustained an apparent life-threatening event or were siblings of infants who had died of SIDS (5) showed reinforced bradycardia after LCR stimulation when performed during exposure to acute hypoxia. This effect was attributed to a potentiating effect from $\mathrm{CB}$ chemoreceptor stimulation. In our study, acute hypoxemia appeared to have a small and inconsistent effect on the heart rate response to laryngeal stimulation in the $\mathrm{C}$ group. However, in the $\mathrm{H}$ lambs, acute hypoxemia enhanced LCR bradycardia significantly and inhibition of ventilation in response to LCR stimulation was diminished. There was a trend for $\mathrm{H}$ lambs to have lower $\mathrm{PaO}_{2}$ before LCR stimulation, so a more powerful CB stimulation could have occurred in these lambs during the LCR apnea response. The increased heart rate response in the $\mathrm{H}$ lambs during acute hypoxemia is consistent with a potentiated bradycardia effect from simultaneous LCR and CB stimulation $(37,40,41)$ and illustrates that the $C B$ in these lambs do not exhibit a generalized dysfunction but function at a lower range of $\mathrm{PaO}_{2}$, because the reset from fetal to adult function had not been completed.

In summary, this study has shown that prolonged hypoxemia after birth alters the maturational changes in the ventilatory response to LCR stimulation. This effect is most likely related to alteration of function of peripheral chemoreceptors caused by a delay in their postnatal reset mechanism. A potential failure to recover from apnea was observed in these lambs. Acute hypoxemia preceding LCR stimulation attenuated the inhibitory effect on ventilation in both $\mathrm{C}$ and $\mathrm{H}$ lambs. Reflex bradycardia was significantly augmented by acute hypoxemia, especially in the $\mathrm{H}$ animals. In both groups, reflex bradycardia correlated with the ventilatory response to LCR stimulation. Results of this study do not confirm the theory that acute hypoxemia preceding apnea reinforces the ventilatory response to LCR stimulation.

Acknowledgments. The authors thank Dr. Mildred T. Stahlman for her support and advice; Stanley Poole, MS, Patricia Minton, RN, and Rao Gaddipati, MS, for their skilled technical assistance; and Donna Staed for typing the manuscript.

\section{REFERENCES}

1. Downing SE, Lee JC 1975 Laryngeal chemosensitivity: a possible mechanism for sudden infant death. Pediatrics 55:640-649

2. Lanier B, Richarson MA, Cummings C 1983 Effect of hypoxia on laryngea reflex apnea: implications for sudden infant death. Otolaryngol Head Neck Surg 91:597-604

3. Lee JC, Stoll BJ, Downing SE 1977 Properties of the laryngeal chemoreflex in neonatal piglets. Am J Physiol 233:R30-R36

4. Saski CT 1979 Development of laryngeal function: etiologic significance in the sudden infant death syndrome. Laryngoscope 89:1964-1982

5. Wennergren G, Hertzerberg T, Milerad J, Bjure J, Lagercrantz H 1989 Hypoxia reinforces laryngeal reflex bradycardia in infants. Acta Paediatr Scand 78:1117

6. Boggs DF, Bartlett Jr D 1982 Chemical specificity of a laryngeal apneic reflex in puppies. J Appl Physiol 53:455-462

7. Kovar I, Selstam U, Catterton WZ, Stahlman MT, Sundell HW 1979 Laryngea chemoreflex in newborn lambs: respiratory and swallowing response to salts, acids, and sugars. Pediatr Res 13:1144-1149

8. Storey AT, Johnson P 1975 Laryngeal water receptors initiating apnea in the lamb. Exp Neurol 47:42-55

9. Harding R, Johnson P, McClelland ME 1978 Liquid-sensitive laryngeal receptors in the developing sheep, cat and monkey. J Physiol (Lond) 277:409422

10. Davies AM, Koenig JS, Thach BT 1989 Characteristics of upper airway chemoreflex prolonged apnea in human infants. Am Rev Respir Dis 139:668-673

11. Perkett EA, Vaughan RL 1982 Evidence for a laryngeal chemoreflex in some human preterm infants. Acta Paediatr Scand 71:969-972

12. Pickens DL, Scheff G, Thach BT 1988 Prolonged apnea associated with upper airway protective reflexes in apnea of prematurity. Am Rev Respir Dis 137:113-118

13. Grogaard J, Lindstrom DP, Stahlman MT, Marchal F, Sundell H 1982 The cardiovascular response to laryngeal water administration in young lambs. J Dev Physiol 4:353-370

14. Grogaard J, Kreuger E, Lindstrom D, Sundell H 1986 Effects of carotid body maturation and terbutaline on the laryngeal chemoreflex in newborn lambs. Pediatr Res 20:724-729

15. Marchal F, Corke BC, Sundell H 1982 Reflex apnea from laryngeal chemostimulation in the sleeping premature newborn lamb. Pediatr Res 16:621627

16. Marchal F, Crance JP, Arnould P 1986 Ventilatory and waking responses to laryngeal stimulation in sleeping mature lambs. Respir Physiol 63:31-41

17. Lucier GE, Daynes J, Sessle BJ 1978 Laryngeal reflex regulation: peripheral and central neural analyses. Exp Neurol 62:200-213

18. Sutton D, Taylor EM, Lindeman RC 1978 Prolonged apnea in infant monkeys resulting from stimulation of superior laryngeal nerve. Pediatrics 61:519527

19. Lawson EE 1981 Prolonged central respiratory inhibition following reflex induced apnea. J Appl Physiol 50:874-879

20. Brady JP, Ariagno RL, Watts JL, Goldman SL, Dumpit FM 1978 Apnea, hypoxemia, and aborted sudden infant death syndrome. Pediatrics 62:686691

21. Hunt CE 1992 Sudden Infant Death Syndrome. In: Beckerman RC. Brouillette RT, Hunt CE (eds) Respiratory Control Disorders in Infants and Children. Williams \& Wilkins, Baltimore, pp 190-211

22. Henderson-Smart DJ, Cohen GL 1988 Chemical control of breathing in early life. In: Schwartz PJ, Southall DP, Valdes-Dapena M (eds) The Sudden Infant Death Syndrome. Cardiac and Respiratory Mechanism and Interactions. NY Academy of Science, New York, pp 276-289

23. Hunt CE, McCulloch K, Brouillette RT 1981 Diminished hypoxic ventilatory responses in near-miss sudden infant death syndrome. J Appl Physiol 50:1313-1317

24. Eden GJ, Hanson MA 1987 Maturation of the respiratory response to acute hypoxia in the newborn rat. J Physiol (Lond) 392:1-9

25. Hanson MA, Kumar P, Williams BA 1989 The effect of chronic hypoxia upon the development of respiratory chemoreflexes in the newborn kitten. J the development of respirat
Physiol (Lond) 411:563-574

26. Sladek M, Grogaard JB, Sundell HW 1990 Delayed resetting of carotid body oxygen sensitivity following prolonged hypoxia in newborn lambs. Pediat Res 27:317A(abstr)

27. Martin-Body RL, Johnston BM 1988 Central origin of the hypoxic depression of breathing in the newborn. Respir Physiol 71:25-32

28. Lawson EE, Long WA 1983 Central origin of biphasic breathing pattern during hypoxia in newborns. J Appl Physiol 55:483-485

29. Tatsumi K, Pickett CK, Weil JV 1991 Attenuated carotid body hypoxic sensitivity after prolonged hypoxic exposure. J Appl Physiol 70:748-755 
30. Canet E, Carroll JL, Bureau MA 1989 Hypoxia-induced periodic breathing in newborn lambs. J Appl Physiol 67:1226-1233

31. van Vliet BN, Uenishi M 1992 Antagonistic interaction of laryngeal and central chemoreceptor respiratory reflexes. J Appl Physiol 72:643-649

32. Grogaard J, van den Abbeele A, Sundell H 1985 Effect of alcohol on apnea reflexes in young lambs. J Appl Physiol 59:420-425

33. Johnson P, Salisbury DM, Storey AT 1975 Apnea induced by stimulation of sensory receptors in the larynx. In: Bosma J, Showcare J, Rockville MD (eds) Development of Upper Respiratory Anatomy and Function. US Dept HEW, Washington, DC, pp 160-178

34. Donnelly DF. Haddad GG 1986 Effect of graded anesthesia on laryngealinduced central apnea. Respir Physiol 66:235-245

35. Hirshman CA, McCullough RE, Cohen PJ, Weil JV 1975 Hypoxic ventilatory drive in dogs during thiopental, ketamine, or pentobarbital anesthesia. Anesthesiology 43:628-634

36. Timms RJ 1982 Central blocking action of ketamine anaesthesia on the visceral alerting and chemoreceptor reflex responses in the cat. Pflugers Arch 394:1215
37. Daly de Burgh $M 1986$ Interactions between respiration and circulation In: Cherniack NS, Widdicombe JG (eds) Handbook of Physiology. The Respiratory System, Vol II Williams \& Wilkins, Baltimore, pp 529-595

38. Angell-James JE, de Burgh Daly M 1978 The effects of artificial lung inflation on reflexy induced bradycardia associated with apnoea in the dog. J Physiol (Lond) 274:349-366

39. Kato H, Menon AS, Slutsky AS 1988 Mechanisms mediating the heart rate response to hypoxemia. Circulation 77:407-414

40. Curzi-Dascalova L, Christova E, Peirano P, Singh BB, Gaultier C, Vicente G 1989 Relationship between respiratory pauses and heart rate during sleep in normal premature and full-term newborns. J Dev Physiol 11:323-30

41. Angell-James JE, de Burgh Daly M 1975 Some aspects of upper respiratory tract reflexes. Acta Otolaryngol 79:242-252

42. de Burgh Daly M, Kirkman E, Wood LM 1988 Cardiovascular responses to stimulation of cardiac receptors in the cat and their modification by changes in respiration. J Physiol (Lond) 407:349-362

43. Kahn A, Blum D, Engleman E, Watershoot P 1982 Effect of central apnea on transcutaneous $\mathrm{PO}_{2}$ in control subject siblings of victims of sudden infant death syndrome and near miss infants. Pediatrics 69:413-418 